New Zealand journal of industrial relations, 1983, 8, 123-132

\title{
The American experience with occupational safety and health regulation
}

\author{
James R. Chelius*
}

The significant changes in American occupational safety and health policies are now over 10 years old. This paper reviews and integrates the empirical studies on the impact of this regulation. The evidence indicates that government mandated safety standards have had little or no beneficial impact on the workplace. Because of the long term nature of the problems, there is no evidence on the effectiveness of health standards; however several studies indicate such standards are quite inefficient. The workers' compensation system which was hoped to have influenced prevention with its price incentives has yielded mixed results. The introduction of the system appears to have enhanced safety; however higher benefits are associated with higher reported accident rates.

The optimal mechanisms for controlling occupational safety and health are not obvious. While the appropriate form of regulation surely varies across countries, much may be learned from other experiences. It is the purpose of this essay to review American occupational safety and health regulation so as to provide a basis for the reader to determine the lessons which are generalisable to their country. Regulation of occupational safety was one of the earliest forms of government intervention in the American workplace. Although such legislation is over 100 years old,${ }^{1}$ its character has dramatically changed in the past decade. This new interest in occupational safety and health has given rise to a substantial number of empirical studies about the workplace impact of such regulation. It is these empirical studies that will be emphasized in this review.

The first section briefly describes the legal structure of regulation which includes both the federal Occupational Safety and Health Act 1970 (OSHAct) and the individual state workers' compensation laws. The survey of empirical results is divided into 2 sections; one on the OSHACt and a second on workers' compensation laws. Current developments in American occupational safety and health regulation are then reviewed followed by a conclusion.

\section{The regulatory framework}

American policy toward occupational safety and health has two fundamental goals: the prevention of accidents and disease and the provision of medical care and income security to injured workers. The government's role in the pursuit of these goals has many facets: however, the policies which form the heart of our regulatory effort are the OSHAct and

* The Author is an Associate Professor and Director of the Occupational Safety and Health Center at the Institute of Management and Labor Relations, Rutgers University, New Brunswick, New Jersey, U.S.A.

1. The first industrial safety law in the United States was passed in Massachusetts in 1877. 
workers' compensation. ${ }^{2}$

The regulation of industrial safety using government-mandated standards and inspectors was carried out at the state level for many years. While no one argued that these modest efforts had a large impact (Sands, 1968; Chelius, 1974) no great problem was perceived because the trend in injury rates was steadily downward. In the 1960's however, injury rates began to rise. This change in injury rates plus a change in political climate which made federal intervention on a wide range of issues much more acceptable, combined to yield the OSHAct. Interestingly, it was subsequently demonstrated that this injury rate increase was, in large part, a reflection of cyclical factors rather than a reversal of the long term trend. The 1960s saw a substantial increase in the number of young and inexperienced workers as well as an unusually long upswing in the level of business activity - both factors being key determinants of the injury rate. (Chelius, 1979) The OSHAct provided for federal government promulgation of safety and health standards which were to be enforced by inspectors with the power to fine erring employers. States were allowed to maintain their own programs if such efforts were certified as being at least as effective as the federal policy.

As part of the OSHAct, Congress established a National Commission to study the states' workers' compensation laws and make recommendations for their reform. (Report, 1972) The Commission heartily endorsed the basic principle of workers' compensation, that is, the no-fault liability of employers for workplace injuries with the quid pro quo of employer immunity from tort actions by employees. While the Commission made many detailed recommendations for the reform of the state laws, the key suggestions were for substantial increases in the compulsory benefits payable to injured workers. If the states did not comply with the key recommendations, the Commission urged the Congress to mandate compliance. Since not all states complied with all recommendations, there were several bills proposed in the Congress during the mid-1970s to mandate benefit levels and other minimum standards for each state's law. These Congressional proposals did not pass, so the workers' compensation system remains based on state statutes. The thrust of the recommendations, however, was embodied in the laws of most states; the Commission largely had its entended impact. Benefit levels for injured workers increased an unprecedented 43 percent in the period from 1972 through 1980, even after adjusting for the impact of inflation. (Worrall, forthcoming)

The dual goals of occupational safety and health policy, prevention and security, are usually thought of as served respectively by the 2 distinct policies of the OSHAct and workers' compensation. It has, however, often been asserted that the workers' compensation system, as well as providing medical and income security to those who become injured, may influence the number of injuries that occur. This assertion is based on the possibility that mandatory benefits to workers create an extra incentive for employers to prevent injuries and disease. Only recently have the prevention possibilities of workers' compensation been subjected to empirical testing. It is this prevention role rather than the security role of workers' compensation which is examined in this review. We begin, however, with the empirical evidence on the OSHAct.

\section{The impact of OSHA}

It is useful to divide the review of the Occupational Safety and Health Administration (OSHA, the agency which administers the OSHAct) into 2 parts; safety and health. Although evaluation of both areas is difficult, the relationship between prevention activities and accidents is not encumbered by a long and uncertain interval as is the case with

2 Other legal systems which are peripherally relevant are tort suits and social security disability insurance. The workers' compensation system is intended as the exclusive remedy for workplace injury liability. There are, however, often tort actions which test the boundary between workers' compensation and the court system. Another relevant social policy is the social security system which provides benefits to totally disabled individuals regardless of the source of their disability. 
prevention and health. We have learned many things about the regulation of health at the workplace but it is frankly much more speculative than our knowledge about occupational safety.

We would like to know whether regulation has been effective; that is, has it had any beneficial impact? However, it is also helpful to know if it has been efficient. This means that given the amount of prevention resources that are spent, does the regulation direct these resources in a manner which maximizes worker well-being? ${ }^{3}$

\section{Safety}

A completely straightforward evaluation of OSHA's impact on safety is not feasible. The data base on industrial injuries was substantially changed with the introduction of the law in 1970. This, of course, makes simple before and after comparisons impossible. Many indirect examinations of its impact have, however, been conducted. The consensus is that OSHA has had only a small or negligible impact on injury rates. Even those most sympathetic to this form of regulation acknowledge that its potential for influencing safety is relatively minor. This occurs because of evidence that a fairly small percentage (10 to 30 percent) of injuries are due to factors potentially controllable by government standards. Even many of those injuries preventable by adherence to standards are due to momentary lapses that are unlikely to be observed by even the most diligent inspection force. Mendelhoff (1979) estimates that only 5 to 10 percent of injuries are due to causes detectable by inspectors (as opposed to the 10 to 30 percent caused by violations of the standards).

The methods used to indirectly measure OSHA's impact on safety are quite diverse. Smith (1979a) compared the injury rate experience of firms inspected early in a year to those inspected late in the year. He reasoned that, if inspections had a beneficial impact on injury rates, this effect would show up more in the annual injury rates of those firms inspected early than those inspected late. The impact of inspections on injury rates in the following year was also examined. The econome tric methodology held a series of other factors constant, including changes in employment levels and prior injury rates. The conclusion was that the 1973 inspections lowered injury rates in small firms. No effect from 1974 inspections was observed. These inconclusive results warranted a follow-up study which was conducted by McCaffrey (forthcoming). This study repeated the same analysis for 1976, 1977 and 1978. He concluded there was no evidence of a beneficial effect on injury rates from OSHA's inspections during these years.

Mendelhoff (1979) used different methods to examine the impact of OSHA. He compared pre and post 1970 injury rates using data from one state's workers' compensation system. The data were refined so that only the type of injuries most likely to be influenced by standards and inspectors was included. These injuries were those resulting from a victim being "caught in or between" machinery. The results indicate that for the early 1970s such injuries were lower than would have been predicted based on past experience; however, the results do not appear to hold up as subsequent years are added to the data base (Viscusi, 1983).

Another study of a single state compared changes in injury rates over the period 1970 to 1976 between inspected and non-inspected firms (Cooke and Gautschi, 1981). They found that inspected firms were more likely to have a decrease in injury rates over this period. The results applied only to firms with more than 200 employees. This same study examined the impact of joint union-management safety committees and found they had a positive effect that was greater than the regulatory impact.

The most comprehensive examination of country-wide data is Viscusi (1979a). He examined the linkage between various OSHA activities, capital investment in safety equip-

3 There are, of course, more global standards by which one might measure OSHA's efficiency. For example, are the prevention resources spent on occupational safety and health as productive as the resources spent on environmental or highway safety and health. Even more generally, efficiency is associated with a condition in which resources are equally productive across all activities in providing satisfaction to individuals. 
ment, and injury rates. No impact of OSHA on either investment or injury rates was discernible.

The net conclusion of these studies is apparent. Some positive results of OSHA have been observed, but even the most optimistic interpretation is one of a small impact. The overall weight of the evidence, is that it has not been significantly effective in improving safety.

\section{Health}

In the United States, there is much more of a consensus on the appropriateness of regulating occupational health than on regulating occupational safety. Many feel that the forces of the private marketplace including unions are able to achieve the desirable amount of safety. The key reasons being that both workers and employers are felt to have sufficient information and motivation as to safety hazards and prevention techniques, and certainly more insight than government agencies into the specific problems of individual worksites. The consistently observed presence of wage premiums for hazardous work (Smith, 1979b) and employer difficulties retaining workers in dangerous environments (Viscusi, 1979b) are often cited as evidence of the working of these market forces. Many of those most critical of OSHA's safety efforts are sanguine about its possibilities in occupational health. While enjoying more support for its potential usefulness, the manner in which OSHA has actually regulated health is quite controversial. The agency has and continues to place its primary effort on safety rather than health; occasional rhetoric to the contrary notwithstanding. In over 10 years only 11 health hazards have been addressed with standards; the number of citations has been miniscule.

The empirical evidence on OSHA's impact is of a different sort than the evidence on safety. The frequently long and uncertain interval between exposure and illness makes workplace testing of the results derived from health standards a task for the future. In many cases, however, we have medical evidence on the likely effectiveness of a particular standard if it is observed. Based on the assumption that they are effective, several policy evaluations have been done on the efficiency of these standards. As defined above, the general notion of efficiency concerns whether prevention resources are mandated in a way which maximizes worker health.

Even raising the issue of policy efficiency is often viewed as evidence of at least stinginess or more likely anti-worker bias. The point, however, is a simple one. Given a limit on our individual and collective willingness to expend resources on prevention, we certainly want to allocate these resources in the manner they do the most good. We would not want to impose a health standard costing $\$ 100$ million and saving 10 lives if that meant not being able to impose an alternative standard costing the same amount and saving 100 lives. Many would, of course, argue that we should do both and perhaps we should; but it maximizes worker well-being if we exhaust the opportunities for greater health improvement before we spend prevention resources in areas with lesser rewards. ${ }^{4}$

The OSHAct mandated that health standards be established which assure, " . . to the extent feasible, .... that no employee will suffer material impairment of health ...". Consistent with the probable intent of Congress, OSHA has usually interpreted "feasible" (and other qualifiers such as " as far as possible" and "insofar as practicable") as meaning technologically possible, rather than efficient.

The Supreme Court has reviewed this issue in 2 recent cases. In a 5 to 4 vote, the Court invalidated a benzene exposure standard stating that a "significant risk" must be demonstrated before a standard is implemented (Benzene, 1980). This affirmed a lower court's ruling that there was no evidence that the standard bore a "reasonable relationship to its

4 The issue of how much we should spend on occupational health improvement compared to other uses of our resources is a difficult one. When making such comparisons, real interest rates (interest rates adjusted for inflation) are most often used as the measure of the productivity of foregone opportunities. 
one-half billion dollar price tag." While OSHA was thereby instructed to focus on significant risks, another recent and closely decided case emphasizes that the agency is not required to balance the costs and benefits of its standards. "[T]o the extent feasible" is to mean simply "capable of being done" (Cotton dust, 1981). The Court's decision, however suggested that OSHA may consider the "least costly alternative" when developing a standard. The latitude available to OSHA as a result of these decisions is currently subject to intense debate. Some contend that "least costly alternative" in combination with the "significant risk" doctrine allows considerable discretion for the agency in its regulation of workplace health. As discussed below in the section on current developments, OSHA seems to be moving ever so slightly in the direction of more flexible workplace health regulation.

The potential gains from attention to efficiency can be seen from the empirical work that has been done on the various health standards. It is worth emphasizing again that the cost of meeting standards is raised here only in the limited context of its implications for maximizing worker well-being. When the cost of reducing a particular risk is minimized, that simply means more prevention resources are available for addressing other risks. In addition, there will probably be greater employer acceptance of and compliance with standards which consider the costs of prevention.

The gains from more flexible regulation are well illustrated by Morrall's (1981a) analysis of the alternatives for controlling cotton dust exposure. It appears that the average cost of engineering controls per byssinois case avoided is over 70 times more expensive than using personal protective equipment. Similar potential gains from flexibility are also apparent from the wide disparities in the inter-industry costs of avoiding hearing impairment. Viscusi (1983) finds that the cost per worker protected ranges from $\$ 39000$ in the electrical equipment industry to $\$ 395000$ in textile mills. Morrall (1979) finds that the relative efficiency in noise protection from engineering controls versus personal protective equipment also varies significantly across industries.

The issue is well summarized by considering the way OSHA standards can influence occupational health. "[W]e can reduce lead in workers' blood below levels linked with serious health effects for $\$ 270000$ per affected worker, eliminate byssinois at $\$ 415000$ per case, reduce hearing loss at $\$ 169000$ per affected worker, eliminate cancer for $\$ 1.8$ million per case, and extend lives for $\$ 4.6$ million [acrylonitrile] to $\$ 13.9$ million [coke ovens particulates] per life." "More lives could be saved for fewer dollars by, for example, loosening the coke oven standard and tightening the acrylonitrile standard." (Viscusi, 1983) While the precision implied by such numbers is specious, the orders of magnitude are instructive. We simply cannot eliminate all risks and, once that is acknowledged, it is sensible to regulate in a manner which generates the greatest results from our efforts. That does not appear to be what we are doing. A much greater beneficial impact on employee health could be achieved if we concentrated on reducing low cost of prevention risks before we pursued high cost risks. A policy which observed this simple rule while also encouraging the least-cost method of prevention for each risk, would minimize the resources available for dealing with other occupational health problems.

\section{The evidence of workers' compensation}

As already mentioned, workers' compensation is potentially important to both goals of occupational safety and health policy; prevention and security. As to the security goal, the evaluation of the changes in workers' compensation during the past decade is relatively straightforward. From 1972 to 1980 (the latest available year) benefits per $\$ 100$ of wages increased over 43 percent. Moreover, nearly all states now increase benefits automatically each year because benefit maximums are a function of average wage levels. As a result of statutory changes during the 1970s, the level of financial security available to injured workers is at an all time high.

It has long been hypothesized that workers' compensation may also serve the prevention goal. The mechanism being that employers spend more on prevention when there are 
workers' compensation costs to be saved; and the greater the workers' compensation benefits to be saved, the more employers would be willing to spend. This simple notion of willingness to spend more to avoid a greater penalty is complicated, however, by the impact workers' compensation might have on employees. In the same manner that workers' compensation benefits increase the cost of an injury to the employer, they reduce the cost of an injury to the worker and thus possibly lessen his or her prevention efforts. In addition, the availability of benefits may increase the reporting of injuries by workers. It is also possible, of course, that workers' compensation has no significant impact on injury rates. The presence and direction of any impact of workers' compensation on injury rates is, therefore, uncertain; many diverse incentives are created by such a system and changes to it. Fortunately, as public attention focused on workers' compensation in the 1970s, a substantial body of empirical evidence accumulated which begins to unravel these complex issues.

The most fundamental issue, that of whether the introduction of workers' compensation influenced injury rates is discussed first. The impact of benefit level changes such as occurred in the 1970 s will then be reviewed.

State workers' compensation laws were passed in the early twentieth century long before systematic high quality data on occupational risks were available. There is, therefore, little empirical evidence on any changes in safety behaviour that may have been induced by these legal changes. Only one study has been conducted on this issue (Chelius, 1976). While the methodology and specific results are reviewed below, the basic conclusion was that the introduction of workers' compensation improved the level of occupational safety.

The data used to represent the level of occupational risks were deaths caused by machinery other than motor vehicles. Such accidents accounted for 16 percent of industrial deaths. Approximately 87 percent of these machinery accidents occurred at the workplace. While these data are only a crude proxy for occupational risks, the state rather than federal nature of the laws, as well as the differing years of enactment, made possible a methodologically precise design for analyzing variations in the data. There are variations in death rates across states each year; some states having workers' compensation laws and some not. There are also variations in death rates within each state over time. For some years a state had a workers' compensation law and for other (earlier) years it did not. A variety of techniques were used to control for the influence of other factors that could have affected death rates. These controlled factors included: per capita exposure to machinery, the business cycle, medical care, age, sex, employers' liability statutes, legislated safety standards, and technological change. Using several alternative specifications, the results were statistically robust; the introduction of workers' compensation was associated with a lower level of work-related deaths.

Prior to the enactment of workers' compensation, the assignment of work injury costs was handled by the courts using both common law and statutory rules for determining negligence. A key perceived defficiency in the negligence system was the low percentage of injured workers who were able to collect damages. Those who were able to collect, however, typically received larger awards than the benefits automatically available under workers' compensation. The change from court judgments to workers' compensation, therefore, was essentially a switch from a low probability of collecting a large payment to a high probability of collecting a small payment. Ashford and Johnson (1982) have compared the "expected values" (probability times amount of compensation) of both systems. This expected value is a measure of the injury costs assigned to the employer. These calculations indicate that it is very likely that the expected value of injury costs assigned to the employer was higher under the 'negligence system than under workers' compensation. This finding, when integrated with the finding that the introduction of a workers' compensation program was associated with a higher level of safety, indicates that the employers' relative certaintly of being assigned injury costs was more critical than the magnitude of the expected value of those costs. In other words, imposing the injury costs on employers in reasonably certain manner appears to have been a key factor in raising the level of occupational safety. 
While the study which examined the introduction of workers' compensation laws considered only the presence or absence of a law, there were many significant ways in which a workers' compensation law might vary. The most significant of these is the level of benefits payable upon injury. We now review these studies of the relationship between benefit levels and injury rates.

As already noted, there may be diverse incentives created by changes in benefit levels. Benefit level increases influence 3 aspects of employee motivation. There is less incentive to avoid accidents, a greater incentive to report injuries that have occurred, and more incentive to prolong the recovery period before returning to work. For employers, higher benefits may induce more prevention activities and increase efforts to return disabled workers to employment. Obviously the incentives to employers and employees from higher benefits are conflicting, and the net effect of benefit levels on injuries can only be determined by empirical investigation.

The first studies of the relationship between benefit levels and safety activities were cross-sectional analyses which examined the inter-state variance in workers' compensation benefits (Chelius, 1974; 1977). These studies found that higher benefit levels were associated with higher injury frequency rates, indicating a dominance of the employee incentives. More recent studies using alternative data sources, time periods, and statistical techniques have confirmed these results. ${ }^{5}$ While injury frequency rates have been found to be higher when benefit levels are higher, this finding must be used with caution. Specifically, it is necessary to consider whether the relationship between benefits and injury rates is the result to more injuries actually occurring or the result of increased reporting of injuries when higher benefits are available.

Two studies have addressed whether the observed positive relationship between benefits and injury rates is a "reporting" phenomenon. In an analysis of the OSHA data for 1972 to 1975,1 study used the frequency of injuries that did not result in lost workdays and found no statistically significant relationship between that rate and benefit levels (Chelius, 1982). Since such injuries are clearly not compensable under any workers' compensation law, these data are unlikely to include injuries workers are reporting only because of workers' compensation benefits. If benefit levels were inducing less prevention by workers, there should be a positive relationship between this non-lost workday injury rate and benefit levels, as there was between benefit levels and the lost workday frequency rate. Thus, rather than differences in prevention efforts, the observed relationships could be due to incentives to falsify injuries or to declare otherwise ignored injuries. Such a test, while not very rigorous, suggests that the association between higher benefits and more injuries may largely be a "reporting" phenomenon.

A contrary conclusion, was reached in Butler's (forthcoming) analysis of a time-series of 1 state's data. He presented 2 reasons why the "reporting" phenomenon does not explain, at least totally, the positive relationship between injury rates and benefit levels. First, he found the highest response to benefit level changes among the more serious injuries. "If only reporting changes were being recorded, we would not be observing the largest increases in claims as benefits rise in the more dangerous death and permanent partial categories." To support this interpretation that worker prevention efforts are decreased when benefits are increased, Butler also asserts that "... [ $t$ ] he significant wage differentials for risk of injury would not be observed if all changes in claims reflected only reporting propensities".

These studies thus provide conflicting views about the importance of the "reporting" phenomenon. Clearly this is an issue that deserves further analysis. While it appears to be a valid finding that observed injury rates are higher when benefits are higher, we are not clear whether this represents the deleterious influence of higher benefits on workers' prevention efforts, the reporting of injuries that otherwise would have been unrecorded, or a combina-

5 These studies are Chelius (1982), Chelius (forthcoming), Butler and Worrall (forthcoming), and McEaffrey (forthcoming) all of which use pooled time-series and cross-section data. Butler (forthcoming) also found a positive relationship benefit levels and injury rate using a long time-series from one state. 
tion of the 2 effects. It is also possible that higher benefits reduce the number of actual injuries (because the higher benefits induce more preventive activities by employers than carelessness by workers), but that the higher benefits lead to such a large increase in reported injuries that the net association between benefits and the injury rate is positive.

Another dimension of the reporting phenomenon is the criteria of eligibility for benefits (compensability). A study of air traffic controllers clearly indicates that if criteria for compensability are loosened, a "reporting" phenomena occurs. Staten and Umbeck (forthcoming) examined the impact of a 1974 change in the Federal Employee Compensation Act which liberalized the standards necessary to demonstrate that one has been psychologically "injured" on the job. This change took place during a period in which workers' compensation benefits available to an "injured" federal employee were substantial. On average, disabled controllers (federal employees) with at least 1 dependent qualified for benefits exceeding their normal take home pay. Since a controller would receive compensation for the duration of disability, more could be made by staying on the compensation rolls than by staying on the job.

After the 1974 legal changes, the number of disability claims based on psychological stress significantly increased. This finding while based on a relatively small work group with a uniquely generous workers' compensation system and an injury that is unusually difficult to evaluate, makes an important point. The incentives transmitted to employers and employees may well influence prevention activities and hence real injury rates. However, a compensation system with generous benefits and a lax definition of what constitutes an injury creates incentives to report a compensable injury when, in fact, one has not occurred.

\section{Current developments}

The Reagan administration has begun to put its imprint on OSHA. As to safety, the primary new direction is the "voluntary protection program". 6 Under this arrangement firms certified as having successful safety programs are exempted from inspections and given priority treatment with any requests for variances from the safety standards. To be eligible a firm must have: an ongoing safety program, an internal employee complaint mechanism, a co-operative atmosphere between the employer and workers, and a good injury rate record. There is no requirement that the employees be represented by a union. Given the evidence on the usefulness of worker management safety committees (Cooke and Gautschi, 1981), encouraging them seems like a good idea. Giving praise and publicity to successful firms is also helpful, but it seems unlikely that the program will have a signicant overall impact. It appears that program participants are going to be the firms which have been doing a good job. The formal rewards of inspection exemption and variance priority are small and therefore unlikely to induce poor performers into significant changes.

On health issues, OSHA is currently reviewing several of its standards with the objective of (at least in the case of lead exposure)

improving the cost-effectiveness of the standard[s] and ... re-evaluating the feasibility of the standard[s] in some industries. If the outcome of this reconsideration is a modification in the mix of engineering controls and personal protective equipment required to meet the permissible exposure limit ... such action would clearly result in major changes in the employers' compliance programs. (OSHA, 1982)

Similar flux in the status of health standards is indicated by the, at least temporary, exemption of the knitting and hosiery industries from the cotton dust standard. The reason is the finding of a medical study that "... indicates little or no excess risk of byssinosis or other pulmonary disease in the knitting sector at the low levels [of exposure] which exist." (OSHA, 1983) Whether these actions portend a basic restructuring of occupational health policy or just the give and take of transitory political squabbles is not clear.

6 Health programs are also included although as of yet no companies are participating on this basis. 
There is currently a substantial amount of legislative activity within the workers' compensation system. The thrust of the changes to this system during the 1970 s was the substantial increase in benefit levels. While benefits as a percentage of wages grew by 43 percent between 1972 and 1980; employer costs grew 66 percent (Worrall, forthcoming). This additional cost was due to the increase in injuries examined above. The response to this increase in employer costs has been a wave of legislative activity to modify the eligibility requirements for benefits. A prime area of concern is injuries classified as "permanent partial disabilities", a significant source of the cost increases. For benefit determination many states are considering a larger role for actual wage losses rather than judgments as to the extent of the partial disability. It is uncertain whether this round of attempted and actual changes to the workers' compensation system will be of any general significance.

Another major activity changing the workers' compensation system is judicial. Workers' compensation has historically immunized employers from employee tort actions. While there have always been court tests of the boundaries of this immunity, the number of cases successfully challenging workers' compensation as the "exclusive remedy" has been unusually large over the past few years. Commentators vary in their assessments as to the long run significance and desirability of these tort actions (Chelius, 1977; Larson, 1982).

\section{Conclusion}

It is clear that American's experience with government regulation of occupational safety and health has not been a successful one. The most optimistic reports indicate only a small impact from OSHA's safety efforts; most conclude it has not yielded any beneficial results. Although it is too early to measure the effectiveness of our health efforts, it appears to be grossly inefficient with only a few hazards covered. The costliness of the health standards, in absolute terms and relative to benefits, has led to widespread industrial resistance and a resulting slow pace in covering further hazards. Simple economies such as considering the difficulty and usefulness of compliance, allowing use of personal protective equipment, and requiring results rather than specific designs are virtually ignored. While the financial security of injured workers has substantially improved over the past decade; this gain has been accomplished at the expense of higher reported injury rates.

This pattern of evidence epitomizes the American experience with much of its regulation from the 1960's and 1970's. A broad set of social problems were observed and a statute and agency assigned the task of providing a remedy. Such a commitment worked with sending a man to the moon; surely it would work with more prosaic problems such as job training, environmental clean-up, and occupational safety and health. The simple truth is that such social problems have proven to be more intractable than the engineering problems of the space age.

In recent years a substantial amount of economic activity has been deregulated, a trend which predated (and perhaps presaged) the Reagan administration. A typical situation was the airline industry where strong restrictions on entry into the industry and federally set prices had yielded a cartel-like situation. A pattern of evidence evolved which indicated that consumers were the losers while companies and their unionized workers gained. The broad consensus on the harm of this regulation is indicated by the fact that Senator Ted Kennedy, a leader of the most liberal faction within Congress, led the fight for deregulation. Similar price and/or entry regulation, largely dating from the 1930's, has been reduced in a wide range of industries; including buses, petroleum, broadcasting, eyeglasses, and railroads. This process reflects the extensive evidence of government failure and public disillusionment with government's role as protector of the public's interest. Interestingly, many academics, particularly economists and political scientists, now study the regulatory process as a device for serving interest groups rather than as a vehicle for the helping society.

This cynicism about government's regulatory role has not spread to the new wave of regulation from the 1960's and 1970's. There is widespread recognition that this new regulation is not accomplishing what was desired, but the response has not been to abandon the 
task. As the evidence of ineffectiveness and inefficiency builds up there are at least 3 directions we might take. One is deregulation such as has occurred with much of the older price and entry regulation. Another, advocated by many economists is to modify the workers' compensation system to make it a true tax on injuries and illnesses; thus making use of and reinforcing the strengths of the marketplace. Third, and most likely, is a continuation of the current regulation with modest and marginal adaptations. We are searching for effective and efficient mechanisms for regulating occupational safety and health. The empirical evidence to date indicates we are a long way from our goals.

\section{References}

Ashford, R.H. and Johnson, W.G. (1982) Negligence vs. no-fault liability: a theoretical and empirical analysis of the workers' compensation example Seton Hall law journal 12 (4) : $725-766$

Butler, R.J. (forthcoming) Wage and injury rate response to shifting levels of workers' compensation In J.D. Worrall (Ed) Safety and the workforce : incentives and disincentives in workers' compensation Ithaca, NY, ILR Press.

Butler, R.J. and Worrall, J.D. (forthcoming) Workers' compensation : benefit and injury claims in the seventies Review of economics and statistics.

Chelius, J.R. (1974) The control of industrial accidents : economic theory and empirical evidence Law and contemporary problems 38 (4) : 700-729.

Chelius, J.R. (1976) Liability for industrial accidents : a comparison of negligence and strict liability systems Journal of legal studies $\mathbf{5}$ (2) : 293-309.

Chelius, J.R. (1977) Workplace safety and health : the role of workers compensation Washington, DC, American Enterprise Institute.

Chelius, J.R. (1979) Economic and demographic aspects of the occupational injury problem Quarterly review of economics and business 19 (2) : 65-70.

Chelius, J.R. (1982) The influence of workers' compensation on safety incentives Industrial and labor relations review 35 (2) : 235-242.

Chelius, J.R. (forthcoming) Workers compensation and the incentive to prevent injuries In J.D. Worrall (Ed) Safety and labor supply : incentives and disincentives in workers' compensation insurance Ithaca, NY, ILR Press.

Cooke, W.N. and Gautschi, F.H. III (1981) OSHA, plant safety programs, and injury reduction Industrial relations 20 (3) : 245-257.

Larson, A. (1982) The exclusive remedy doctrine : commentary, Paper presented at a conference on current trends in the legal environment of workers' compensation sponsored by the National Council on Compensation Insurance, New York.

McCaffrey, D.P. (forthcoming) An assessment of OSHA's recent effects on injury rates Journal of human resources.

Mendelhoff, J. (1979) Regulating safety : an economic and political analysis of occupational safety and health policy Cambridge, Mass., MIT Press.

Morrall, J.F. III (1979) Exposure to occupational noise, In J.C. Miller III and B. Yandle (Eds) Benefit-cost analysis of social regulation Washington, DC, American Enterprise Institute: 33-58.

Morall, J.F. III (1981a) Cotton dust : an economist's view In R. Crandell and F. Lower (Eds) The scientific basis of health and safety regulation Washington, DC, The Brookings Institution: 93-108.

Morrall, J.F. III (1981b) OSHA after ten years, paper presented for Conference on health, safety, and environmental regulation, Washington, DC, American Enterprise Institute. 
OSHA (1982) Notice of workplace lead standard administrative stay for the smelting and battery manufacturing industries Federal register 47FR 54433 December 3, 1982.

OSHA (1983) Occupational safety and health administration notice of cotton dust standard stay for knitting operations Federal register 48 FR 52; February 4, 1983.

The Report of the National Commission on State Workmen's Compensation Laws (1972) Washington, DC, Government Printing Office.

Sands, P.E. (1968) How effective is safety legislation? Journal of law and economics 11 : $165-179$.

Smith, R.S. (1979a) The impact of OSHA inspections on manufacturing injury rates Journal of human resources 14 (2) : 145-170.

Smith, R.S. (1979b) Compensating wage differentials and public policy : a review Industrial and labor relations review 32 (3) : 339-352.

Staten, M. and Umbeck, J. (forthcoming) Information costs, insurance contracts and a theory of fraud with special application to the air traffic control industry In J.D. Worral (Ed) Safety and the workplace : incentives and disincentives in workers' compensation Ithaca, NY, ILR Press.

Viscusi, W.K. (1979a) The impact of occupational safety and health regulation The Bell journal of economics 10 (1) : 117-140.

Viscusi, W.K. (1979b) Employment Hazards : an investigation of market performance Cambridge, Mass., Harvard University Press.

Viscusi, W.K. (forthcoming, 1983) Risk by choice : regulating health and safety in the workplace Cambridge, Mass., Harvard University Press.

Worrall, J.D. (forthcoming) Introduction In J.D. Worrall (Ed) Safety and the workforce : incentives and disincentives in workers' compensation Ithaca, NY, ILR Press.

\section{List of cases}

Benzene, 1980: Industrial Union Department, AFL - CIO v. American Petroleum Institute, et al. and Marshall v. American Petroleum et al., US Supreme Court, July 2, 1980.

Cotton dust, 1981: American Textile Manufacturers Institute, Inc. et al. v. Donovan and National Cotton Council of America v. Donovan, US Supreme Court, June 17, 1981. 